\title{
Lodo de esgoto no crescimento do "mosquitinho" (Gypsophila elegans)
}

\author{
Título Sewage sludge on "mosquitinho" (Gypsophila elegans) growth
}

Sara Moreno Pereira Lacerda ${ }^{1 *}$, Joseane Oliveira da Silva ${ }^{2}$, Felizardo Adenilson Rocha ${ }^{2}$

\begin{abstract}
RESUMO
O objetivo deste trabalho foi avaliar a eficiência da utilização do lodo de esgoto no crescimento do mosquitinho. O experimento foi realizado na Casa de Vegetação do Instituto Federal de Educação Ciência e Tecnologia (IFBA) - Campus de Vitória da Conquista, Bahia. O delineamento foi blocos casualizados (DBC), em esquema fatorial ( $2 \times 4)$, os tratamentos corresponderam a dois níveis de calagem e quatro doses de lodo de esgoto, com três repetições, totalizando 24 unidades experimentais, constituindo os seguintes tratamentos: T1: $0 \mathrm{Mg} \mathrm{ha}^{-1}$ de Lodo da ETE; T2: $8 \mathrm{Mg} \mathrm{ha}^{-1}$ de Lodo da ETE; T3: $16 \mathrm{Mg} \mathrm{ha}^{-1}$ de Lodo da ETE; T4: $24 \mathrm{Mg} \mathrm{ha}^{-1}$ de Lodo da ETE. Foram avaliados Massa seca da parte aérea (MSPA), Massa Seca da Raiz (MSR), Massa Seca Total (MST), Taxa de crescimento relativo (TCR), Taxa assimilatória líquida (TAL) e Índice de colheita (IC). O uso do lodo de esgoto favoreceu o acúmulo da massa seca da planta, incremento da AF, TCR, TAL e IC. A dose $24 \mathrm{Mg} \mathrm{ha}^{-1}$ na presença do calcário dolomítico proporcionou um incremento da AF, TCR e IC.
\end{abstract}

Palavras-chave: Composto orgânico; Fisiologia vegetal; Mosquitinho.

\begin{abstract}
The objective of this work was to evaluate the efficiency of the use of sewage sludge in the growth of the mosquito. The experiment was carried out at the Vegetation House of the Federal Institute of Science and Technology Education (IFBA) - Vitória da Conquista Campus, Bahia. The design was randomized blocks (DBC), in a factorial scheme $(2 \times 4)$, the treatments corresponded to two levels of liming and four doses of sewage sludge, with three replications, totaling 24 experimental units, constituting the following treatments: T1: $0 \mathrm{Mg} \mathrm{ha}^{-1}$ of ETE Sludge; T2: $8 \mathrm{Mg} \mathrm{ha}^{-1}$ of ETE Sludge; T3: $16 \mathrm{Mg} \mathrm{ha}^{-1}$ of ETE Sludge; T4: 24 $\mathrm{Mg} \mathrm{ha}^{-1}$ of Sludge from the ETE. Shoot Dry Mass (MSPA), Root Dry Mass (MSR), Total Dry Mass (MST), Relative Growth Rate (RCR), Net Assimilation Rate (TAL) and Harvest Index (CI) were evaluated. The use of sewage sludge favored the accumulation of plant dry mass, increase of AF, TCR, TAL and CI. The dose of $24 \mathrm{Mg} \mathrm{ha}^{-1}$ in the presence of dolomitic limestone provided an increase in AF, TCR and CI.
\end{abstract}

Keywords: Organic compost; Plant physiology; Mosquitinho.

\footnotetext{
${ }^{1}$ Universidade Estadual do Sudoeste da Bahia - UESB.

*E-mail: saramp16@gmail.com

${ }^{2}$ Instuto Federal de Educação Ciência e Tecnologia da Bahia - IFBA
} 


\section{INTRODUÇÃO}

A floricultura brasileira tem sido favorecida pelas condições climáticas, que contribuem para a produção de diversas flores, folhagens e derivados. (VIDAL et al., 2022). Uma preferência entre os consumidores se dá pelas flores de corte, em função do seu efeito decorativo, perfume, e por propiciar beleza e harmonia a diferentes ambientes, seu cultivo vem se tornando essencial para a economia, gerando milhares de empregos diretos e indiretos (BOTELHO et al., 2015).

Para Neves e Pinto (2015), dentre as flores de corte encontradas no país, a gipsófila tem se destacado. Isso se deve à sua beleza e aplicabilidade, pois esta flor apresenta grande versatilidade, podendo ser usada como flor de vaso, além de compor arranjos florais ou ser usada como flor seca (ZAGO et al., 2015).

Para garantir aumento na produtividade da gipsófila, os produtores recorrem a adubos, que podem ser de origem química ou orgânica (HIRANAKA et al., 2005). Dentre os diversos tipos de adubo orgânico, o lodo de esgoto é considerado uma boa alternativa e sua utilização gera benefícios como a incorporação de nutrientes ao solo, matéria orgânica, promove retenção de água, além de proporcionar a deposição de serrapilheira, promovendo a ciclagem de nutrientes (IBRAHIM et al., 2019; LOBO et al., 2018).

Muitos estudos têm mostrado resultados positivos do uso do lodo de esgoto como fertilizante orgânico, os resultados mostram que houve aumentos na produção de massa seca (BARONE et al., 2018), área foliar (SIQUEIRA et al., 2019) e índices fisiológicos (BERTOLAZI et al., 2017).

Diante do exposto, este trabalho teve como objetivo avaliar a eficiência do lodo de esgoto no crescimento da Gypsophila elegans.

\section{MATERIAIS E MÉTODOS}

O experimento foi conduzido na casa de vegetação, localizada no IFBA, campus Vitória da Conquista. O delineamento adotado foi em Blocos Casualizados (DBC), em esquema fatorial ( $2 \times 4)$, os tratamentos correspondem a dois níveis de calagem e quatro doses de lodo de esgoto, com três repetições, totalizando 24 unidades experimentais.

Considerando-se a recomendação para uso agrícola de $17 \mathrm{Mg} \mathrm{ha}^{-1}$ de lodo de esgoto em base seca para a cultura da Gypsophila paniculata L., feita por Wachowicz e 
Serrat (2006), utilizou-se diferentes proporções de lodo de esgoto, constituindo os seguintes tratamentos: T1: $0 \mathrm{Mg} \mathrm{ha}^{-1}$ de Lodo da ETE; T2: $8 \mathrm{Mg} \mathrm{ha}^{-1}$ de Lodo da ETE ; T3: $16 \mathrm{Mg} \mathrm{ha}^{-1}$ de Lodo da ETE; T4: $24 \mathrm{Mg} \mathrm{ha}^{-1}$ de Lodo da ETE;

O solo utilizado foi o Latossolo Vermelho Amarelo Distrófico, coletado na profundidade de 0 a $20 \mathrm{~cm}$. Após a coleta, o solo foi seco ao ar, destorroado, peneirado. Cada vaso recebeu $3 \mathrm{~kg}$ de solo. Foi realizada uma análise do solo para caracterização química, de acordo com a metodologia adotada pela Embrapa (1997), conforme está apresentado na Tabela 1.

Tabela 1: Resultado da análise química do solo utilizado no experimento antes da implantação.

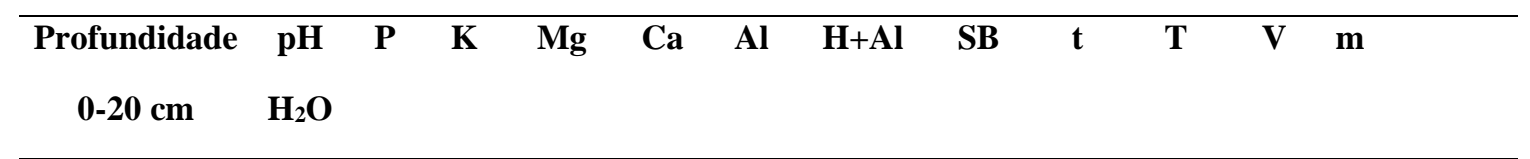

\begin{tabular}{lllllllllllll}
\multicolumn{1}{c}{} & \multicolumn{1}{c}{$\mathrm{mg} \mathrm{dm}^{-3}$} & & & & & $\%$ \\
\hline LVA & 5,6 & 6,6 & 91 & 0,57 & 1,18 & 0,1 & 2,31 & 1,98 & 2,08 & 4,29 & 46,2 & 4,8
\end{tabular}

Fonte: UFV - Laboratório de solos (2021).

Após a caracterização química do solo, foi observado que o mesmo se encontrava ácido. Segundo Hiranaka et al. (2005), o pH ideal para o cultivo da gipsófila deve estar em torno de 6,5 e a saturação de bases a $80 \%$. Deste modo foi realizada a correção da acidez utilizando 1,8450 gramas por vaso de calcário dolomítico com o PNRT $83 \%$ em 12 vasos. Após a aplicação do calcário, o solo permaneceu úmido e incubado por 30 dias, tempo necessário para que ocorresse a reação do calcário e posterior neutralização do hidrogênio.

O lodo de esgoto utilizado no experimento foi fornecido pela Empresa Baiana de Águas e Saneamento (EMBASA), coletado na Estação de Tratamento de Esgoto - ETE, situada no município de Vitória da Conquista, Bahia. Antes da implantação do experimento, o lodo da ETE, foi amostrado para determinação das características químicas (Tabela 02), conforme metodologias propostas pela Embrapa (1997). O lodo foi incorporado ao solo 30 dias antes do plantio. 
Tabela 2: Resultado da análise química do lodo de esgoto antes da implantação do experimento.

Identificação

$\begin{array}{llllllllllllllll}\text { da amostra } & \mathrm{N} & \mathrm{P} & \mathrm{K} & \mathrm{Ca} & \mathrm{Na} & \mathrm{Mg} & \mathrm{S} & \mathrm{CO} & \mathrm{C} / \mathrm{N} & \mathrm{Zn} & \mathrm{Fe} & \mathrm{Mn} & \mathrm{Cu} & \mathrm{B} & \mathbf{p H}\end{array}$

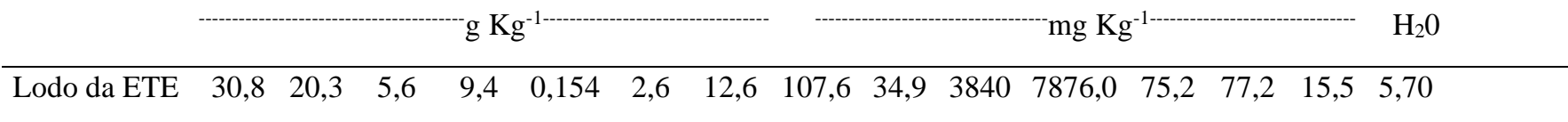

Fonte: UFV - Laboratório de solos (2021).

Foram utilizadas sementes de Gypsophila elegans, popularmente conhecida como mosquitinho, adquiridas em lojas agropecuárias, marca feltrin, tratadas com $0,15 \%$ de THIRAM (dados informados pelo fabricante). As sementes foram germinadas em bandejas de isopor contendo substrato vegetal. Após a germinação as mudas foram transplantadas para os vasos contendo como substrato amostras de solo e o lodo de esgoto. A rega das mudas ocorreu diariamente, onde cada vaso recebeu $250 \mathrm{~mL} \mathrm{dia}^{-1}$ de água.

As avaliações de crescimento foram realizadas no dia do transplante e no dia da colheita, esta última ocorreu aos 107 dias após o transplante (DAT). As plantas foram colhidas e separadas em parte aérea e raízes. As folhas frescas de cada planta foram identificadas e analisadas com auxílio de scanner no programa WinFolia Pro 2012a (REGENT INSTRUMENTS, 2012), para determinação da área foliar (AF, em $\mathrm{cm}^{2}$ ). Também foi realizada a determinação da massa fresca e posteriormente todo o material foi colocado para secagem em estufa a $65^{\circ} \mathrm{C}$ com ventilação forçada por $48 \mathrm{~h}$, até obtenção de massa seca constante (MS) em balança semi analítica. Os dados de MS e AF obtidos foram utilizados para obtenção dos parâmetros de crescimento, segundo Benincasa (2003), no intervalo de 107 dias, entre o transplante e a colheita.

Assim, foi calculada segundo a metodologia apresentada por Benincasa (2003) a taxa de crescimento relativo (TRC) que representa o incremento na massa de matéria seca (MS) por unidade de peso inicial, em um intervalo de tempo (T) (equação 1).

$$
\operatorname{TCR}\left(g g^{-1} d i a^{-1}\right)=\frac{\ln \mathrm{MS} 2-\ln \mathrm{MS} 1}{\mathrm{~T} 2-\mathrm{T} 1}
$$


Foi calculada a taxa assimilatória líquida (TAL), que representa a taxa de incremento de massa seca (W) por unidade de área foliar (AF) existente na planta, assumindo que tanto AF como W, aumentam exponencialmente (West et. al., 1920) de acordo com a equação 2 .

$$
\mathrm{TAL}\left(g d m^{-1} d i a^{-1}\right)=\frac{\mathrm{W} 2-\mathrm{W} 1}{\mathrm{AF} 2-\mathrm{AF} 1} * \frac{\mathrm{LnAF} 2-\mathrm{LnAF} 1}{\mathrm{~T} 2-\mathrm{T} 1}
$$

Também foi obtido o índice de colheita (equação 3), que é definido como a razão entre a massa seca da fração econômica produzida (flor) e a massa seca total colhida. Desse modo, utilizou-se a massa seca da parte aérea (MSPA em g) e a massa seca total (MST em g) aos 107 DAT.

$$
\text { IC }\left(\text { planta }^{-1}\right)=\frac{\text { MSPA }}{\text { MST }}
$$

Os dados foram submetidos à análise de variância (ANOVA). Foram avaliadas as independências dos erros, a normalidade dos dados pelo teste Kolmogorov-Smirnov, e foi testada a homogeneidade de variância dos erros utilizando o teste de Bartlett a $5 \%$ de probabilidade. Os dados de massa seca da raiz foram transformados em $\log (\mathrm{x})$, em que $\mathrm{x}$ representa a massa seca da raiz $(\mathrm{g})$, em todas as tabelas são apresentados os dados transformados. Em seguida realizou-se a análise de regressão em função das doses do lodo da ETE, utilizando o programa Statistical Analysis System (SAS).

\section{RESULTADOS E DISCUSSÃO}

Massa Seca da Parte Aérea (MSPA), Massa Seca da Raiz (MSR) e Massa Seca Total (MST)

Na Tabela 3 são apresentados os dados referentes à massa seca da parte aérea (MSPA), massa seca da raiz (MSR) e massa seca total (MST). A interação entre correção da acidez e doses do lodo de esgoto foi significativa $(\mathrm{P}<0,05)$ para as três variáveis. 
Tabela 3: Massa Seca da Parte Aérea (MSPA) (g), Massa Seca da Raiz (MSR) (g), Massa Seca Total (MST) (g) da Gypsophila elegans, na presença do calcário dolomítico (CD) e na ausência do calcário dolomítico (SC) e adubadas com lodo de esgoto.

\begin{tabular}{|c|c|c|c|c|c|}
\hline \multicolumn{6}{|c|}{ Doses do Lodo de Esgoto } \\
\hline Calcário dolomítico & & MSPA $(g)$ & & & \\
\hline & $0 \mathrm{Mg} \mathrm{ha}^{-1}$ & $8 \mathrm{Mg} \mathrm{ha}^{-1}$ & $16 \mathrm{Mg} \mathrm{ha}^{-1}$ & $24 \mathrm{Mg} \mathrm{ha}^{-1}$ & Média \\
\hline Presença (CD) & $13,54^{\mathrm{a}}$ & $16,85^{\mathrm{b}}$ & $30,043^{\mathrm{a}}$ & $33,17^{\mathrm{a}}$ & 23,4000 \\
\hline Ausência (SD) & $8,68^{\mathrm{b}}$ & $33,32^{\mathrm{a}}$ & $25,38^{\mathrm{b}}$ & $22,23^{\mathrm{b}}$ & 22,4008 \\
\hline Média & 11,11 & 24,59 & 27,71 & 27,70 & \\
\hline $\mathrm{CV}(\%)$ & & & & & 9,86 \\
\hline Calcário dolomítico & & $\operatorname{MSR}(\mathrm{g})$ & & & \\
\hline Presença (CD) & $1,533^{\mathrm{a}}$ & $1,223^{\mathrm{a}}$ & $1,530^{\mathrm{a}}$ & $1,423^{\mathrm{b}}$ & 1,4967 \\
\hline Ausência (SD) & $1,143^{\mathrm{b}}$ & $1,417^{\mathrm{a}}$ & $1,650^{\mathrm{a}}$ & $1,776^{\mathrm{a}}$ & 1,4283 \\
\hline Média & 1,338 & 1,320 & 1,590 & 1,599 & \\
\hline $\mathrm{CV}(\%)$ & & & & & 9,65 \\
\hline Calcário dolomítico & & $\operatorname{MST}(\mathrm{g})$ & & & \\
\hline Presença (CD) & $18,297^{\mathrm{a}}$ & $20,306^{\mathrm{b}}$ & $34,693^{\mathrm{a}}$ & $37,313^{\mathrm{a}}$ & 27,652 \\
\hline Ausência (SD) & $11,827^{\mathrm{b}}$ & $37,460^{\mathrm{a}}$ & $30,593^{b}$ & $28,157^{b}$ & 27,009 \\
\hline Média & 15,062 & 28,883 & 32,643 & 32,735 & \\
\hline $\mathrm{CV}(\%)$ & & & & & 8,04 \\
\hline
\end{tabular}

Médias seguidas de letras distintas na coluna diferem pelo teste $\mathrm{F}(\mathrm{P}<0,05)$.

Fonte: Elaborado pelos autores

Observa-se para MSPA, MSR e MST que houve diferença estatística $(\mathrm{P}<0,05)$ entre a presença e ausência do calcário dolomítico na maior parte dos tratamentos.

Para a massa seca da parte aérea do mosquitinho as doses 0,16 e $24 \mathrm{Mg} \mathrm{ha}^{-1}$ proporcionaram um maior incremento na MSPA na presença do calcário de 55\%, $18 \%$ e $49 \%$ respectivamente em relação a mesma dose na ausência da calagem. $\mathrm{Na}$ dose $8 \mathrm{Mg}$ $\mathrm{ha}^{-1}$ a MSPA foi favorecida pela ausência do calcário dolomítico em $97 \%$ em relação à dose na presença da calagem. Assim, nota-se que a adição do lodo de esgoto e calcário dolomítico favoreceu o aumento da massa seca da parte aérea das plantas. Martins et al. (2018), avaliando o crescimento inicial do milho, decorrente da aplicação do lodo de esgoto e resíduo de poda urbana, observaram que a adubação orgânica também proporcionou um aumento da massa seca da parte aérea da cultura.

Em termos de massa seca da raiz, observa-se que na dose $24 \mathrm{Mg} \mathrm{ha}^{-1}$, na ausência da calagem, houve um incremento da MSR de 24\% quando comparado a mesma dose na presença da calagem. Quando realizada a correção da acidez do solo, o maior incremento da MSR foi observado quando presente na dose $0 \mathrm{Mg} \mathrm{ha}^{-1}$ (Tabela 3). Para os demais tratamentos, estatisticamente não houve diferença para massa seca da raiz.

Analisando a MST, as doses 0,16 e $24 \mathrm{Mg} \mathrm{ha}^{-1}$ apresentaram um incremento na presença do calcário de $54 \%, 13 \%$ e $32 \%$ respectivamente em relação a mesma dose na 
ausência da calagem. Na dose $8 \mathrm{Mg} \mathrm{ha}^{-1}$ houve um aumento de $84 \%$ da MST na ausência do calcário dolomítico quando comparado a sua presença. Deste modo observa-se que as maiores doses do lodo de esgoto juntamente com a correção da acidez contribuem para o aumento da MST da gipsófila. Esses resultados foram semelhantes para MSPA.

Lacerda et al. (2022), trabalhando com lodo de esgoto na produção de mudas da margarida, encontraram resultados que corroboram com os obtidos neste estudo, onde a aplicação do lodo de esgoto favoreceu um incremento na massa seca total.

Na Figura 1 está apresentada a análise de regressão, observa-se que a adubação orgânica utilizando o lodo de esgoto influenciou a MSPA, MSR e MST ( $\mathrm{P}<0,05)$, o qual, os maiores valores foram obtidos na dose de $8 \mathrm{Mg} \mathrm{ha}^{-1}$, tanto para MSPA quanto para MST, na ausência do calcário (SD).

$\mathrm{Na}$ presença da calagem, observa-se que a gipsófila obteve o maior valor de MSPA e MST na dose $24 \mathrm{Mg} \mathrm{ha}^{-1}$ de lodo. Os resultados mostram que quanto maior a dose do lodo de esgoto na presença do calcário dolomítico, maior é a MSPA e MST da gipsófila. Resultados semelhantes foram relatados por Lanzeti et al. (2021), trabalhando com Acacia polyphylla, em diferentes concentrações de lodo de esgoto. Os autores encontraram as maiores médias para MSPA na dose $100 \%$ de lodo e afirmaram que, à medida que se aumentava a concentração de lodo no substrato, maior a MSPA.

Garcia et al. (2010), ao avaliar o crescimento de mudas de eucalipto submetidas a aplicação de biossólido, também encontraram resultados que concordam com os obtidos neste estudo, onde o aumento das doses do lodo proporcionou o aumento da massa seca total das plantas de eucalipto.

Figura 1: (A) Massa seca da Parte Aérea, (B) Massa seca total, (C) Massa seca da Raiz, da (Gypsophila elegans) em função da aplicação de diferentes doses de lodo de esgoto na presença (CD) e ausência (SD) do calcário dolomítico

(A)

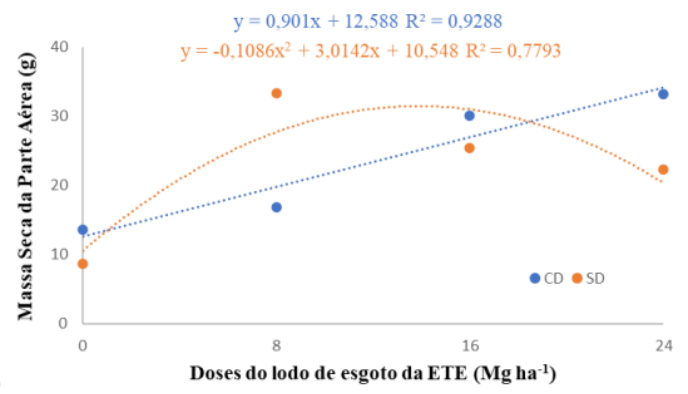

(B)

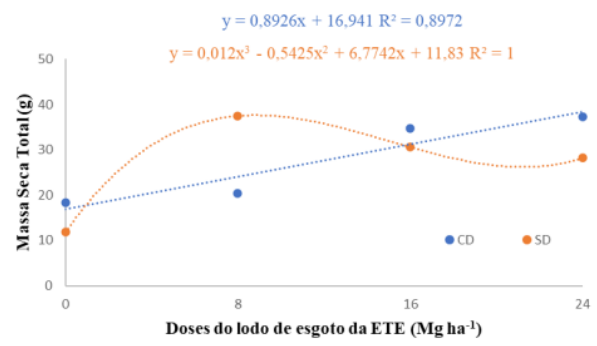

Doses do lodo de esgoto da ETE (Mg ha-1) 


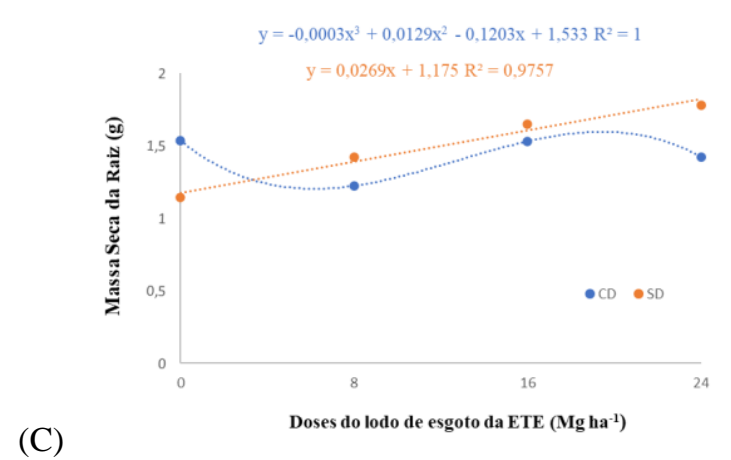

Fonte: Elaborado pelos autores

De acordo com o modelo de regressão ajustado (Figura 1), a MSR na presença do calcário obteve seu maior valor nas doses 0 e $16 \mathrm{Mg} \mathrm{ha}^{-1}$ e a partir daí houve um decréscimo. Para a ausência da calagem (SD) o maior valor de MSR foi observado na dose $24 \mathrm{Mg} \mathrm{ha}^{-1}$.

Ferraz e Poggiani (2014) trabalhando com diferentes lodos de esgoto, encontraram resultados contrários aos encontrados neste trabalho. Os autores afirmaram que a massa de raízes finas produzida pelas árvores de Eucalyptus grandis não apresentaram diferenças estatísticas entre os diferentes lodos de esgoto e o plantio sem qualquer adubação.

Área Foliar (AF), Taxa de Crescimento Relativo (TCR), Taxa Assimilatória Líquida (Tal) e Índice de Colheita (IC).

Na Tabela 4 são apresentados os dados referentes à Área Foliar (AF), Taxa de Crescimento Relativo (TCR), Taxa Assimilatória Líquida (TAL), e Índice de Colheita (IC).

Tabela 4: Área Foliar (AF) $\left(\mathrm{cm}^{2}\right)$, Taxa de Crescimento Relativo (TCR) $\left(\mathrm{g} \mathrm{g}^{-1} \mathrm{dias}^{-1}\right)$, Taxa Assimilatória Líquida (TAL) $\left(\mathrm{g} \mathrm{dm}^{-2} \mathrm{dia}^{-1}\right)$, Índice de Colheita $\left(\mathrm{g} \mathrm{planta}^{-1}\right)$ da Gypsophila elegans, na presença (CD) e ausência (SD) do calcário dolomítico e adubadas com lodo de esgoto

\begin{tabular}{|c|c|c|c|c|c|}
\hline \multicolumn{6}{|c|}{ Doses do Lodo de Esgoto } \\
\hline Calcário dolomítico & & & $\left.n^{2}\right)$ & & \\
\hline & $0 \mathrm{Mg} \mathrm{ha}^{-1}$ & $8 \mathrm{Mg} \mathrm{ha}^{-1}$ & $16 \mathrm{Mg} \mathrm{ha}^{-1}$ & $24 \mathrm{Mg} \mathrm{ha}^{-1}$ & Média \\
\hline Presença (CD) & 249,849 & 250,210 & 348,810 & 353,75 & $300,65^{\mathrm{a}}$ \\
\hline Ausência (SD) & 188,529 & 315,527 & 308,806 & 320,665 & $283,38^{\mathrm{a}}$ \\
\hline Média & 219,189 & 282,869 & 328,808 & 337,208 & \\
\hline $\mathrm{CV}(\%)$ & & & & & 15,77 \\
\hline Calcário dolomítico & & & $\left(\mathrm{g} \mathrm{g}^{-1} \operatorname{dias}^{-1}\right)$ & & \\
\hline Presença (CD) & $0,0293^{\mathrm{a}}$ & $0,0303^{\mathrm{a}}$ & $0,0337^{\mathrm{a}}$ & $0,0353^{\mathrm{a}}$ & 0,03215 \\
\hline Ausência (SD) & $0,0253^{\mathrm{b}}$ & $0,0333^{\mathrm{a}}$ & $0,0336^{\mathrm{a}}$ & $0,0333^{\mathrm{a}}$ & 0,03137 \\
\hline Média & 0,0273 & 0,0318 & 0,03365 & 0,0343 & \\
\hline
\end{tabular}




\begin{tabular}{|c|c|c|c|c|c|}
\hline $\mathrm{CV}(\%)$ & & & & & 5,88 \\
\hline Calcário dolomítico & & & $\mathrm{g} \mathrm{dm}^{-2} \mathrm{dia}$ & & \\
\hline Presença (CD) & $0,0018^{\mathrm{a}}$ & $0,0020^{\mathrm{b}}$ & $0,0028^{\mathrm{a}}$ & $0,00296^{\mathrm{a}}$ & 0,00239 \\
\hline Ausência (SD) & $0,0019^{a}$ & $0,0032^{\mathrm{a}}$ & $0,0027^{\mathrm{a}}$ & $0,00237^{\mathrm{a}}$ & 0,00254 \\
\hline Média & 0,0017 & 0,0026 & 0,00275 & 0,00267 & \\
\hline $\mathrm{CV}(\%)$ & & & & & 15,90 \\
\hline Calcário dolomítico & & & planta $\left.^{-1}\right)$ & & \\
\hline Presença $(\mathrm{CD})$ & $0,7333^{\mathrm{a}}$ & $0,8266^{\mathrm{a}}$ & $0,8633^{\mathrm{a}}$ & $0,89000^{\mathrm{a}}$ & 0,8283 \\
\hline Ausência (SD) & $0,7333^{\mathrm{a}}$ & $0,8866^{\mathrm{a}}$ & $0,8266^{\mathrm{a}}$ & $0,78666^{\mathrm{b}}$ & 0,8083 \\
\hline Média & 0,7333 & 0,8566 & 0,8448 & 0,8383 & \\
\hline $\mathrm{CV}(\%)$ & & & & & 4,67 \\
\hline
\end{tabular}

Médias seguidas de letras distintas na coluna diferem pelo teste $\mathrm{F}(\mathrm{P}<0,05)$.

Fonte: Elaborado pelos autores

A interação entre correção da acidez e doses do lodo de esgoto não foi significativa $(\mathrm{P}>0,05)$ para Área Foliar $(\mathrm{AF})$, ou seja, os fatores atuam independentes. Para Taxa de Crescimento Relativo (TCR), Taxa Assimilatória Líquida (Tal) e Índice de Colheita, a interação foi significativa $(\mathrm{P}<0,05)$.

Ao avaliar a área foliar na presença do calcário, verifica-se que está apresenta um incremento em seu valor à medida que se aumenta as doses do lodo de esgoto. Apesar do aumento da AF, não houve diferenças estatísticas significativas entre as dosagens e presença ou ausência da correção da acidez (Tabela 4). Beckmann-Cavalcante et al. (2015), trabalhando com produção de inflorescências de helicônia cv. Golden Torch sob adubação nitrogenada e potássica, encontraram resultados que corroboram com os obtidos neste estudo, onde o aumento das doses do potássio favoreceu um aumento da área foliar do helicônia, até a dose $120 \mathrm{~g} \mathrm{cova}^{-1}$, a partir desta dose houve uma estabilização da AF.

A TCR expressa o incremento na massa seca, por unidade de peso inicial, em um intervalo de tempo (BENINCASA, 2003). Esa taxa teve diferença estatística somente na dose $0 \mathrm{Mg} \mathrm{ha}^{-1}$ entre presença e ausência do calcário dolomítico, onde a presença da calagem favoreceu o maior valor da TCR. Para os demais tratamentos não houve diferença estatística ao nível de 5\% de probabilidade.

Apesar de não ter apresentado diferenças estatísticas para a maioria dos tratamentos, ao avaliar o fator presença de calcário, observa-se que à medida que as doses do lodo de esgoto foram aumentando houve um incremento da TCR, e a maior taxa de crescimento relativo foi obtida na dose $24 \mathrm{Mg} \mathrm{ha}^{-1}$ na presença da calagem. Braga et al. (2010), avaliando o crescimento do girassol e a aplicação de nitrogênio, obtiveram 
resultados semelhantes a este estudo, onde houve um aumento da taxa de crescimento relativo em função do aumento das doses de nitrogênio.

Sendo a taxa assimilatória líquida (TAL) o acúmulo de massa seca produzida por unidade de área foliar, indicando assim a eficiência das folhas para produção de biomassa (BENINCASA, 2003). observa-se que somente na dose $8 \mathrm{Mg} \mathrm{ha}^{-1}$ houve diferença estatística e a ausência do calcário favoreceu o maior valor de TAL, com um aumento de $60 \%$ em relação a mesma dose na presença do calcário. Em seguida houve um decréscimo na TAL à medida que se aumentava as doses do lodo de esgoto.

Na presença do calcário dolomítico o comportamento da TAL foi similar ao que ocorreu para MSPA e AF, onde os valores das variáveis aumentaram de acordo com o aumento das doses. A ocorrência do aumento da área foliar provocou elevação da fotossíntese líquida e consequentemente aumento da TAL, mas não houve diferença estatística entre as doses 0,16 e $24 \mathrm{Mg} \mathrm{ha}^{-1}$.

Zucarelli et al. (2010), trabalhando com adubação fosfatada no feijoeiro, encontraram resultados semelhantes aos obtidos neste estudo, onde a TAL aumentou durante o ciclo da cultura para todas as doses de fósforo avaliadas. Cruz et al. (2015), avaliando a influência da adubação fosfatada sobre o crescimento do camapu (Physalis angulata L.), observaram que a TAL não apresentou diferença estatística entre nenhum dos tratamentos, deste modo a taxa assimilatória líquida não foi influenciada pelas doses de fósforo, contradizendo os resultados obtidos neste estudo.

O Índice de Colheita tem como objetivo avaliar a eficiência da planta em translocar fotoassimilados para as flores, deste modo, o maior IC demonstra melhor eficiência de conversão de produtos sintetizados em material de importância econômica (CRUZ et al., 2011).

O IC apresentou diferença estatística somente na dose $24 \mathrm{Mg} \mathrm{ha}^{-1}$, onde a presença do calcário dolomítico favoreceu o maior IC. De acordo com Peixoto et al. (2005), para ser considerado satisfatório o valor do IC deve ser superior a $0,5 \mathrm{~g} \mathrm{planta}^{-1}$. Neste estudo o menor IC obtido foi na dose $0 \mathrm{Mg} \mathrm{ha}^{-1}\left(0,73 \mathrm{~g} \mathrm{planta}^{-1}\right)$, e o maior valor de IC foi de 0,90 g planta $^{-1}$ na dose $24 \mathrm{Mg} \mathrm{ha}^{-1}$, sendo considerado, portanto, satisfatório.

$\mathrm{Na}$ análise de regressão observa-se que a adubação orgânica utilizando o lodo de esgoto influenciou a AF, TCR, TAL e IC $(\mathrm{P}<0,05)$ e a equação de regressão que melhor se ajustou aos dados está apresentada na Figura 2. 
Figura 2: Área Foliar $\left(\mathrm{cm}^{2}\right)$, Taxa de Crescimento Relativo $\left(\mathrm{g} \mathrm{g}^{-1}\right.$ dias $\left.^{-1}\right)$, Taxa Assimilatória Líquida $\left(\mathrm{g} \mathrm{dm}^{2} \operatorname{dia}^{-1}\right)$, Índice de Colheita (g planta $\left.{ }^{-1}\right)$, do mosquitinho (Gypsophila elegans) em função da aplicação de diferentes doses de lodo de esgoto, na presença do calcário dolomítico

(A)

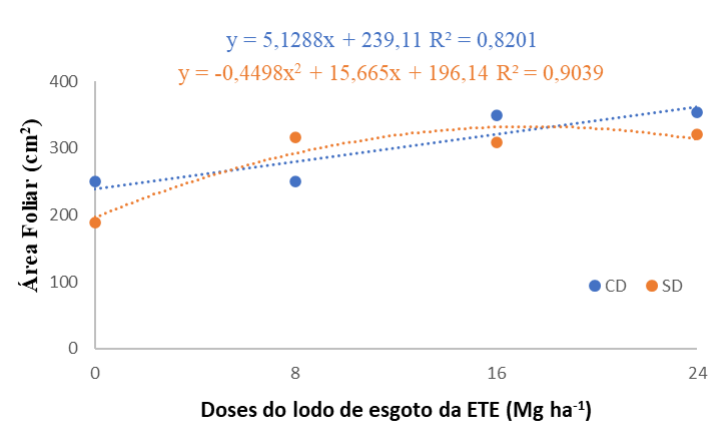

(C)

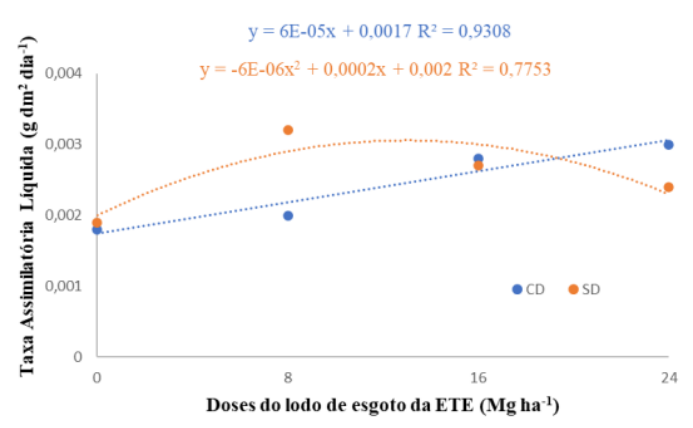

(B)

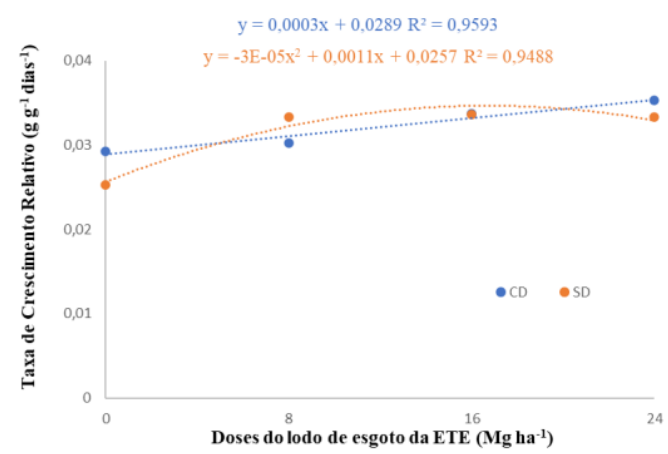

(D)

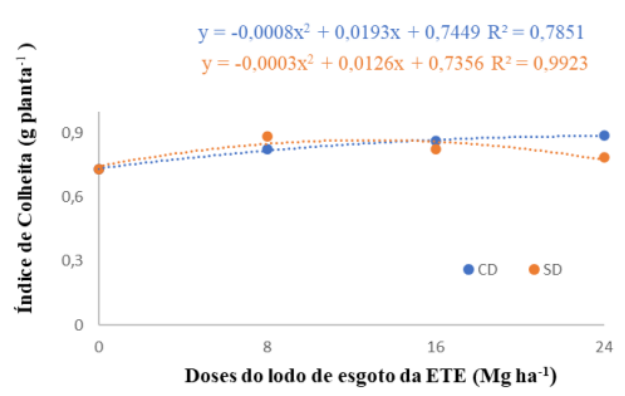

Fonte: Elaborado pelos autores

De acordo com a análise de regressão, verifica-se que para $\mathrm{AF}$, tanto na presença quanto na ausência do calcário dolomítico, o aumento das doses do lodo de esgoto, em geral favoreceu um incremento da área foliar da gipsófila. Isso ocorreu pois o lodo de esgoto promove a melhoria do solo, consequentemente contribuindo para o aumento da AF. Furtado et al. (2017), avaliando os índices fisiológicos do girassol em função da adubação com biocarvão e NPK, também obtiveram um aumento da AF em função das doses do NPK.

A TCR, na presença do calcário dolomítico apresentou um crescimento linear, à medida em que se aumentava as doses do lodo de esgoto, sendo o seu maior valor obtido na dose $24 \mathrm{Mg} \mathrm{ha}^{-1}\left(0,0353 \mathrm{~g} \mathrm{~g}^{-1} \operatorname{dias}^{-1}\right)$. Para a ausência do calcário dolomítico, é notório 
que a TCR teve um incremento em seu valor até a dose $16 \mathrm{Mg} \mathrm{ha}^{-1}$, onde foi obtido o valor máximo de TCR $\left(0,0336 \mathrm{~g} \mathrm{~g}^{-1}\right.$ dias $\left.^{-1}\right)$ depois houve um decrescimento.

Cerqueira et al. (2016), estudando os efeitos das doses de nitrogênio nas respostas morfofisiológicas de coentro (Coriandrum sativum L.), encontraram resultados semelhantes, onde houve um aumento da TCR em função do aumento das doses de $\mathrm{N}$ até a dose $60 \mathrm{Kg} \mathrm{ha}^{-1}$, em seguida houve uma redução da taxa de crescimento relativo.

De acordo com a análise de regressão (Figura 2 C), a TAL na presença do calcário dolomítico teve um crescimento à medida que se aumentava as doses do lodo de esgoto e o maior valor foi obtido na dose $24 \mathrm{Mg} \mathrm{ha}^{-1}\left(0,00296 \mathrm{~g} \mathrm{dm}^{2} \mathrm{dia}^{-1}\right)$. A TAL na ausência do calcário, teve um crescimento até a dose $8 \mathrm{Mg} \mathrm{ha}^{-1}\left(0,0032 \mathrm{~g} \mathrm{dm}^{2} \mathrm{dia}^{-1}\right)$ e a partir desta dose o valor da taxa assimilatória líquida foi diminuindo.

Machado et al. (2011), trabalhando com híbridos de girassol em sistemas de plantio direto, encontraram resultados contrários a este estudo. Aos 105 dias após a emergência, foram observados valores negativos para TAL para quase todos os cultivares, o que mostra um decrescimento da variável em função do crescimento da planta que levou a um sombreamento e consequentemente uma diminuição da TAL.

Ao observar a aplicação das doses do lodo de esgoto e o fator calcário no cultivo da gipsófila, nota-se que houve um aumento dos índices de colheita, para presença e para a ausência do calcário. O maior IC, foi obtido na dose $24 \mathrm{Mg} \mathrm{ha}^{-1}$ na presença da calagem.

\section{CONCLUSÃO}

A produção de massa seca, área foliar, taxa de crescimento relativo, taxa assimilatória líquida e índice de colheita, responderam positivamente à adubação utilizando lodo de esgoto.

Para MSPA, MST, AF, TCR, TAL e IC, no mosquitinho, a dose $24 \mathrm{Mg} \mathrm{ha}^{-1}$ na presença do calcário dolomítico proporciona a melhor resposta dos parâmetros acima citados. Na ausência do calcário dolomítico, a dose $8 \mathrm{Mg} \mathrm{ha}^{-1}$ favorece o maior incremento da MSPA, MST, TAL e IC da planta, a dose $16 \mathrm{Mg} \mathrm{ha}^{-1}$ promove um aumento da MSR e da TCR.

$\mathrm{Na}$ dose $24 \mathrm{Mg} \mathrm{ha}^{-1}$ na presença do calcário dolomítico são obtidos os maiores valores de AF, TCR e IC. Portanto, para o cultivo da gipsófila a dose mais indicada é 24 $\mathrm{Mg} \mathrm{ha}^{-1}$ na presença da calagem. 


\section{AGRADECIMENTOS}

À Coordenação de Aperfeiçoamento de Pessoal de Nível Superior (CAPES) e ao Programa de Pós-graduação em Ciências Ambientais (PPGCA) da Universidade Estadual do Sudoeste da Bahia - UESB pela concessão da bolsa de estudo.

\section{REFERÊNCIAS}

BENINCASA, M. M. P. Análise de crescimento de plantas (8 ações Básicas). Ed. 2. Rev.Ampl. Jaboticabal: FUNEP, 2003, 41p.

BARONE, E.P.; SILVA, F. A. M.; FERRAZ, M. V. Aproveitamento do lodo de esgoto e da casca de palmito na produção de mudas de Lantana câmara. 2018. Brazilian Journal of Biosystems Engineering, v. 12, p. 132-143.

BECKMANN-CAVALCANTE, M. Z.; AMARAL, G. C.; AVELINO, R. C.; SILVA, A. A.; SILVA, A. de S. e; OLIVEIRA, J. B. da S. Produção de inflorescências de helicônia cv. Golden Torch sob adubação nitrogenada e potássica. Comunicata Scientiae, 6(1): 65-73, 2015.

BERTOLAZI, K. B.; AFÁZ, D. C. DE S.; VIANI, R. A. G.; SOUZA, C. F. Viabilidade da aplicação de composto de lodo de esgoto no cultivo inicial de eucalipto. Revista Ciência, Tecnologia \& Ambiente, 2017. http://dx.doi.org/10.4322/2359-6643.04110.

BOTELHO, F. B. S.; RODRIGUES, C. S.; BRUZI, A. T. Ornamental Plant Breeding. Ornamental Horticulture, V. 21, No.1, 2015, p. 9-16.

BRAGA, C. de L.; FERNANDES, D. M.; SIRTOLI L. F.; LUDWIG, F. Análise de crescimento de girassol ornamental de vaso e aplicação de nitrogênio. Scientia Agraria Paranaensis, Volume 9, número 2, 2010, p. 52 - 59.

CERQUEIRA, F. B.; SANTANA, S. C.; SANTOS, W. F. dos; FREITAS, G. A. de; NUNES, T. V.; SIEBENEICHLER, S. C. Doses de nitrogênio nas respostas morfofisiológicas de coentro (coriandrum sativum L.). Gl. Sci Technol, Rio Verde, v.09, n.01, p. $15-21,2016$.

CRUZ, J.C.; MAGALHÃES, P.C.; PEREIRA FILHO; I. A.; MOREIRA, J. A. A. Milho: o produtor pergunta, a Embrapa responde. Embrapa Informação Tecnológica. Brasília, DF: 338 p, 2011.

CRUZ, J. L.; SOUZA FILHO, L.F.S.; PELACANI, C.R. Influência da adubação fosfatada sobre o crescimento do camapu (Physalis angulata L.). Rev. Bras. Pl. Med., Campinas, v.17, n.3, p.360-366, 2015. https://doi.org/10.1590/1983-084X/13_060. 
EMBRAPA. Centro Nacional de Pesquisa de Solos. Serviço nacional de levantamento e conservação do solo. Manual de métodos de análise de solo. Rio de Janeiro: Embrapa Solos, 1997. 212p.

FERRAZ, A. de V.; POGGIANI, F.; Biomassa, nutrientes e metais pesados em raízes de eucaliptos adubados com diferentes lodos de esgoto. Cerne, Lavras, v. 20, n. 2, p. 311-320, abr./jun. 2014.

FURTADO, G. de F.; CHAVES, L. H. G.; SOUZA, L. de P.; SOUSA JUNIOR, J. R. de; LIMA, G. S. de; SOUSA, J. R. M de. Índices fisiológicos do girassol em função da adubação com biocarvão e NPK. Rev. Bras. Agric. Irr. v. 11, nº 7, Fortaleza, p. 1924 1933, 2017.

GARCIA, G. de O.; GONÇALVES, I. Z.; MADALÃO, J. C.; NAZÁRIO, A. A. REIS, E. F. dos; Crescimento de mudas de eucalipto submetidas à aplicação de biossólidos. Revista Ciência Agronômica, v. 41, n. 1, p. 87-94, jan-mar, 2010.

HIRANAKA, N.; BARONE, F. P.; MINAMI, K.; Produção de Gypsophila. Serie Produtor Rural $-\mathrm{n}^{\circ}$ 28. Piracicaba, 2005. Disponível em < https://www.esalq.usp.br/biblioteca/sites/default/files/publicacoes-avenda/pdf/SPR28.pdf >. Acesso em maio 2021.

IBRAHIM, J. F. De O. N.; SILVA JUNIOR, I, V. da; PAEZ, F. Da C. B. D. R. M.; NASCENTES, A. L.; BATISTA DA SILVA, L. D. B. da. Utilização do lodo de esgoto na produção de mudas e no cultivo do eucalipto (Eucalyptus spp). Braz. J. Anim.

Environ. Res., Curitiba, v. 2, n. 1, p. 564-579, jan./mar. 2019.

LACERDA, S. M. P.; SILVA, J. O. da; ROCHA, F. A.; OLIVEIRA, J. T. de.; SILVA, T. O. da; NORONHA, R. H. de F.; ALMEIDA, T. F. de; FERRAZ, L. L.

Reaproveitamento do lodo de esgoto da ete do município de vitória da conquista na produção de mudas da Leucanthemum maximum. Brazilian Journal of Development, Curitiba, v.8, n.1, p.1279-1288jan.2022. DOI:10.34117/bjdv8n1-082.

LANZETI, N. G. A. A.; CHIMINI, A. C.; STANCARE NETO, M..; DA PAZ, M. F.; SIQUEIRA, M. V. B. M. Lodo de esgoto compostado e diferentes lâminas de irrigações no desenvolvimento de Acacia polyphylla. Journal of Biotechnology and Biodiversity | v.9,n.2, 2021. DOI https://doi.org/10.20873/jbb.uft.cemaf.v9n2.lanzeti.

LOBO, T. F.; GRASSI FILHO, H.; BULL, L. T.; KUMMER, A. C. B.; SOUZA, F. L. P. de; Desenvolvimento e nutrição do girassol com lodo de esgoto e nitrogênio. Revista em Agronegócio e Meio Ambiente, Maringá (PR), 2018. DOI: 10.17765/21769168.2019v12n1p173-193.

MACHADO, G. da S.; PEIXOTO, C. P.; SILVA, M. R. da; CRUZ, T. V. da; PASSOS, A. R. Crescimento de híbridos de girassol em sistema plantio direto no Recôncavo da Bahia. Enciclopédia Biosfera, Centro Científico Conhecer - Goiânia, vol.7, N.13; 2011.

MARTINS, C.; SANTOS, F. dos; PORTZ, A.; SANTOS, A. dos. Desenvolvimento inicial do milho (Zea mays L.) em substrato contendo lodo de esgoto compostado. 
2018. Revista Brasileira de Ciências Ambientais (Online), https://doi.org/10.5327/Z2176-947820180305.

NEVES, M. F.; PINTO, M. J. A.; Mapeamento e Quantificação da Cadeia de Flores e Plantas Ornamentais no Brasil. São Paulo: OCESP, 2015. Disponível em < https://www.researchgate.net/profile/Lourival-Monaco-

Neto/publication/304156137_Mapeamento_e_Quantificacao_da_Cadeia_de_Flores_e_P lantas_Ornamentais_no_Brasil/links/576841f708aef9750b0f9cb0/Mapeamento-eQuantificacao-da-Cadeia-de-Flores-e-Plantas-Ornamentais-no-Brasil.pdf >. Acesso em maio 2021.

PEIXOTO, J. R.; BERNADES, S. R.; SANTOS, C.M.; BONNAS, D. S.; FIALHO, J. F.; OLIVEIRA, J. A. Desempenho agronômico de variedades de mandioca mansa em Uberlândia. Revista Brasileira de Mandioca, v. 18, n. 1, p.19-24, 2005.

SIQUEIRA, D. P.; CARVALHO, G. C. M. W. de; BARROSO, D. G. MARCIANO, C. R. Lodo de esgoto tratado na composição de substrato para produção de mudas de Lafoensia glyptocarpa. Floresta, Curitiba, PR, v. 48, n. 2, p. 277-284, abr/jun. 2018. DOI: $10.5380 /$ rf.v48 i2.55795.

WACHOWICZ, C. M.; SERRAT, B.M.; Parâmetros morfológicos de Gypsophila paniculata L. cultivada com lodo de esgoto alcalinizado e adubação fosfatada. Estud. Biol., v. 28, n. 65, p. 51-58, out./dez. 2006.

WEST, C.; BRIGGS, G. E.; KIDD, F. Methodos and significant relations in the quantitative analysis of planta growth. New Physiologist, v. 19: p. 200-207, 1920.

VIDAL, A. M. R. K.; ARAÚJO, J. B. C. N.; GASPAR, R. O.; JOAQUIM, M. S.; SOUZA, A. N. Perfil socioeconômico do produtor de flores e plantas ornamentais do Distrito Federal. Revista de Economia e Sociologia Rural, 60(3), e214505, (2022). https://doi.org/10.1590/1806-9479.2021.214505.

ZAGO, A. P.; MENEGAES, J. F.; BACKES, F.A. L.; BELLÉ, R. A. Complementos de arranjos e buquês florais. Informe técnico, ISSN: $1984-6126$ N. 52/2015.

Disponível em<

https://www.ufsm.br/app/uploads/sites/370/2019/10/InformeTecnico_52_2015.pdf>.Ac esso em mar. 2021.

ZUCARELI, C.; RAMOS JUNIOR, E. U.; MARIANA ALVES DE OLIVEIRA, M. A. DE; CAVARIANI, C.; JOÃO NAKAGAWA, J. Índices biométricos e fisiológicos em feijoeiro sob diferentes doses de adubação fosfatada. Semina: Ciências Agrárias, Londrina, v. 31, suplemento 1, p. 1313-1324, 2010.

Recebido em: 20/01/2022

Aprovado em: 21/02/2022

Publicado em: 24/02/2022 